\title{
Effects of lesions of the caudate nucleus or frontal neocortex on drug-induced seizures in the rat
}

\author{
ROBERT J. KIRKBY \\ Lincoln Institute, Melbourne, 3053, Australia
}

\begin{abstract}
Pentamethylentetrazol-induced seizures were investigated in laboratory rats with bilateral lesions involving the anterodorsal caudate nuclei or the anterior neocortices. In comparison to control subjects, the caudotomized rats were significantly more affected by the seizureproducing effects of the drug. This was reflected in longer episodes of generalized seizures and higher incidences of myoclonus status epilepticus and postseizure mortality. The subjects with ablations of anterior cortical areas showed significantly longer latencies to myoclonus and generalized seizures. The findings supported earlier studies suggesting a specific role for the caudate nucleus in seizure behavior.
\end{abstract}

Several investigations have reported changes in seizure phenomena following destruction of parts of the caudate. One of the first of these studies was that of Spiegel, Wycis, Baird, and Szekely (1956), who reported that seizures in a young boy were relieved by electrolytic destruction of a convulsive focus located in the caudate nucleus with accompanying lesions in the ipsilateral pallidum. In a later study, Mullan, Vailati, Karasick, and Mailis (1967) observed that even small lesions restricted entirely to the caudate nucleus lowered the threshold to hexaflurodiethylether-induced seizures in cats. Unfortunately, this finding was reported as an incidental observation; no information regarding size of samples, verification of lesion sites, or quantified changes in seizure thresholds was given.

Adler $(1965,1966)$ found that lesions of anterior or posterior areas of the cortex lowered the susceptibility of rats to pentylenetetrazol or hexaflurodiethylether-induced seizures. Adler's (1965) observations indicated that rats with cortical lesions involving caudate or hippocampal tissue were not more susceptible to seizures than subjects with cortical damage alone. In a later publication, Adler (1969) reported that following lesions of the caudate nucleus, globus pallidus, or substantia nigra, seizure thresholds in the rat were unaltered. Again, as no information was supplied regarding the extent and precise location of lesions or the size of the experimental sample, evaluation of this report is difficult.

One study with well-documented histology was that of Kesner (1966) who reported that lesions of the caudate nucleus increased the severity and frequency of sound-induced seizures in rats. However, most of the caudate-lesioned brains in this study showed considerable capsular and pallidal encroachment. The involvement of the globus pallidus in seizure activity has been indicated by several investi- gators (Walker, Andy, \& Poggio, 1955; Wycis, Baird, $\&$ Spiegel, 1966). This suggests that the marked changes in seizure susceptibility reported by Kesner (1966) could have resulted from pallidal rather than striatal damage.

From the studies reviewed above, it can be seen that evidence has been provided for and, to a lesser extent, against the involvement of the caudate nucleus in seizure activity. It is unfortunate that in most cases the value of this evidence is clouded by the failure to report histological verification of the area or extent of caudate damage.

To further investigate the role of the caudate nucleus in seizure phenomena, the present study was undertaken. As Gastaut, Naquet, and Fischer-Williams (1958) have emphasized, seizures precipitated by pentylentetrazol mimic epileptic seizures; thus, to make the results of the present investigation more meaningful to the problems of epilepsy, pentamethylentetrazol was used to induce the seizures.

\section{Method}

\section{Subjects}

Thirty-six adult male Wistar albino rats supplied by the C.S.I.R.O. Clunies Ross Laboratories served as subjects. The rats had previously been used in a study of reactivity involving equivalent treatment for all subjects. A complete description of this treatment has been reported (Kirkby, 1973). During the experimental period, rats were housed singly with free access to food and water.

Twelve rats had multiple lesions placed bilaterally in the corpus striatum, 12 rats had multiple lesions placed bilaterally in the frontal cortex, and 12 rats served as unoperated controls. Full details of the two-stage surgical procedure have been reported by Kirkby (1973). At the time of surgery, the rats were approximately 120 days old and weighed between 350 and $450 \mathrm{~g}$.

\section{Procedure}

The experiment took place approximately 70 days after surgery. A wooden box, with internal dimensions $33 \times 22 \times 30 \mathrm{~cm}$ high, 
served as apparatus. The box was coated inside and out with brown varnish and was covered with a clear acrylic lid. Pilot studies indicated that seizure phenomena ranging from myoclonic jerks to grand mal convulsions could be precipitated reliably with pentamethylentetrazol ("Cardiazol"; Knoll), at dose levels of $3-6 \mathrm{mg} / \mathrm{kg}$, IP.

The experimental procedure was as follows: The rat was removed from its home cage, weighed, and injected with pentamethylentetrazol, $4 \mathrm{mg} / \mathrm{kg}$, IP. Immediately following the injection, the animal was placed in the observation box positioned on the floor of the experimental room away from direct illumination. Two experimenters sat on opposite sides of the box. One investigator timed the latencies from time of injection to the onset of seizure phenemona while the other recorded latencies and used a small handcounter to tally myoclonic jerks. Each animal was observed for a 30-min period, then returned to its home cage. In the case where the experimental procedure proved fatal, the subject was taken immediately to the histology room and the brain was removed and placed in Formalin.

Although the appearance of regrown hair indicated which rats had undergone surgery, it was not possible to distinguish the animals with caudate nucleus lesions from those with cortical lesions. To this extent, the study was blind. On the basis of previous findings (Demetrescu, 1967; Gastaut, Naquet, \& FischerWilliams, 1958; Kesner, 1966; Mutani, 1969), it was predicted that the caudate-lesioned subjects, as compared with the unoperated rats, would evidence heightened severity of seizures as reflected in increased incidence of myoclonus, longer episodes of generalized and grand mal seizures, and increased incidence of status epilepticus and postseizure death.

\section{RESULTS}

\section{Histological Results}

The histological procedure has been outlined previously (Kirkby, 1973). The extent of caudate damage is shown in Figure 1. Examination of the subcortical lesions indicated that they involved predominately the upper half of the corpus striatum and could be described generally as lesions of the dorsalcentral aspect of the caudate nucleus, situated between 7.5 and $9.0 \mathrm{~mm}$ anteriorly. Extrastriatal damage beyond that resulting from penetration of the electrode was slight. Seven brains showed some unilateral destruction of corpus callosum tissue. In one brain, callosal involvement was bilateral. Typically, damage was restricted to the most inferior aspects of the corpus callosum. The lesions had penetrated the ventricular wall in three brains. In one of these, the damage was bilateral. In two brains, the lesion continued beyond the ventricle, involving in one brain the nucleus lateralis septi (unilaterally) and in the other the hippocampal commisure and fornix (unilaterally). One brain showed slight damage to the globus pallidus and another damage to the nucleus accumbens septi. In both cases, involvement was restricted to one hemisphere.

The extent of frontal cortex damage is shown in Figure 2. Examination of the cortical lesions showed that generally they were tapered, involving more tissue closer to the surface of the cortex. In three brains, the lesions were relatively shallow, being
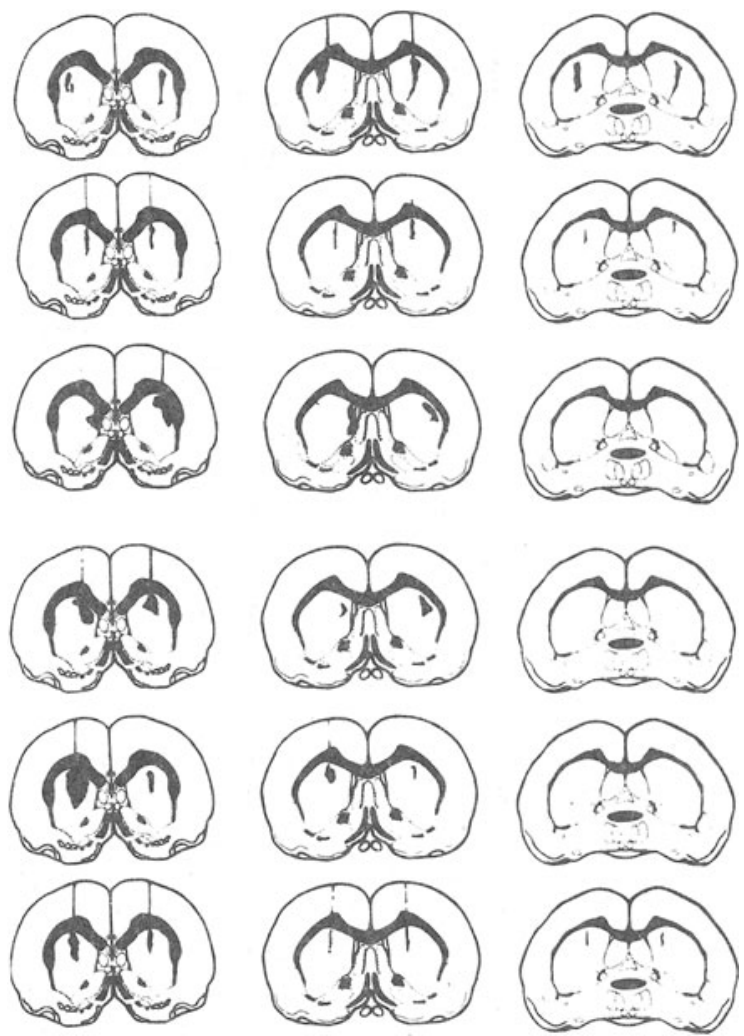

Figure 1. Extent of caudate nucleus damage in representative brains. Sketched from the frozen block, and superimposed on on coronal sections A7.4, 8.6, and 9.0 from de Groot (1959).

restricted to the more superior layers of the cortex. Five additional brains showed damage to the level of the corpus callosum (two bilaterally). In these five brains, the lesion descended to but did not penetrate callosal tissue. Four brains showed damage to the corpus callosum. In three of these, damage was restricted to one hemisphere. Although the lesions in two brains projected deeply into callosal tissue, they did not extend into the underlying corpus striatum. In all 12 animals of the cortical group, the lesions involved bilaterally the area frontopolaris (10), area precentralis (agranularis) (6), and area gigantopyramidalis (4), (Krieg, 1946).

\section{Behavioral Results}

The results are summarized in Table 1 .

Latency to myoclonic jerks. Analysis of variance indicated that differences existed between the groups $(\mathrm{F}=3.53 ; \mathrm{df}=2,33 ; \mathrm{p}<.05)$. The differences were further analyzed by the Neuman-Keuls procedure for post hoc comparisons (Winer, 1962), revealing that the difference between the unoperated and caudotomized groups was not significant $\left(\mathrm{q}^{2}<1\right.$; $\mathrm{df}=33$ ). However, latencies to onset of myoclonic jerks were significantly greater for the frontal group 


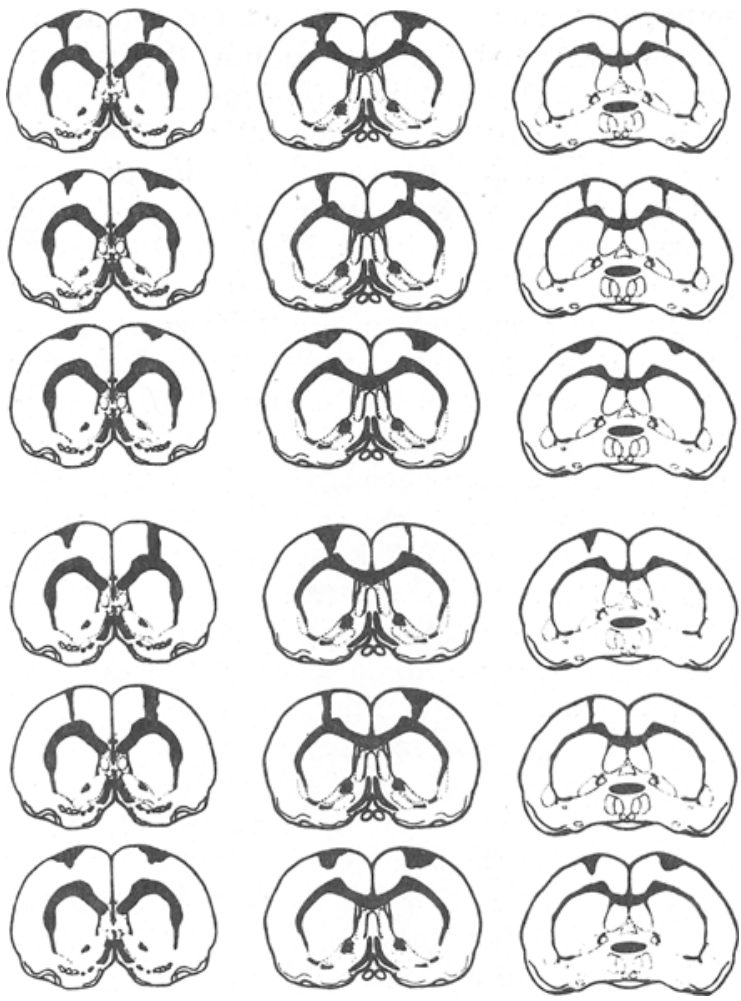

Figure 2. Extent of frontal cortex damage in representative brains. Sketched from the frozen block and superimposed on coronal sections A7.4, 8.6, and 9.0 from de Groot (1959).

than for either the caudate nucleus $\left(q^{2}=3,27\right.$; $\mathrm{df}=33 ; \mathrm{p}<.05)$ or the unoperated groups $\left(\mathrm{q}^{2}=\right.$ 3.49; $\mathrm{df}=33 ; \mathrm{p}<.05)$.

Incidence of myoclonic jerks. The distribution of scores appeared to be negatively skewed. To deal with this uneven spread, differences between groups were compared using the Mann-Whitney $U$ test. As predicted, the caudotomized rats showed a higher incidence of myoclonic jerks than either the cortically lesioned $(\mathrm{U}=28 ; \mathrm{df}=12,12 ; \mathrm{p}<.01$; one-tailed $)$ or the unoperated rats $(U=22 ; \mathrm{df}=12,12$; $\mathrm{p}<.001$; one-tailed). Incidence of myoclonic jerks was higher for the cortically lesioned than for the unoperated rats $(\mathrm{U}=37$; $\mathrm{df}=12,12 ; \mathrm{p}<.05$; twotailed).
Latency to generalized seizure (involving loss of posture). Analysis of variance indicated that differences between groups were significant $(F=3.30$; $\mathrm{df}=2,33 ; \mathrm{p}<.05)$. Further analyses by the NeumanKeuls procedure revealed that differences between the unoperated and caudate nucleus groups $\left(\mathrm{q}^{2}<1\right.$; $\mathrm{df}=33$ ) and frontal cortex and caudate nucleus groups $\left(\mathrm{q}^{2}=2.37\right.$; $\left.\mathrm{df}=33\right)$ were not significant. Latencies for the cortically lesioned group were significantly greater than those of the unoperated subjects $\left(q^{2}=3.56 ; d f=33 ; p<.05\right)$.

Duration of generalized seizures. As specific predictions had been made, the differences in seizure duration were investigated by use of the planned contrasts analysis of variance technique (Hays, 1963). The caudotomized rats showed significantly longer episodes of generalized seizures than unoperated rats $(\mathrm{F}=2.88 ; \mathrm{df}=2,33 ; \mathrm{p}<.05$; one-tailed test $)$. The scores of the frontal cortex group fell in between those of the caudate and unoperated groups.

Incidence of status epilepticus (where clonic and tonic components of the seizure were evident for 15 min or longer). Differences between groups were tested as proportions using Fisher's exact probability test. As predicted, a significantly higher proportion of caudotomized rats than unoperated rats developed status epilepticus $(p<.05$; one-tailed). Proportions of frontal cortex lesion and unoperated rats showing status epilepticus did not differ. The difference between caudate nucleus and frontal cortex rats was not significant.

Incidence of death. Significantly more caudate nucleus lesion rats than unoperated rats had succumbed by the end of the observation period (Fisher's exact probability test, $\mathrm{p}<.5$; two-tailed test). Differences between the frontal cortex lesion and unoperated or caudate lesion groups were not significant.

Brain behavior relationships. Spearman rank order correlations were carried out between extent of neural damage and incidence of various seizure phenomena. Significant correlations were found between the extent of caudate nucleus damage and the duration of generalized seizures $(+.52 ; p<.05)$ and extent of frontal cortex damage and latency to onset of generalized seizures $(+.59 ; \mathrm{p}<.05)$.

Table 1

Effects of Lesions on Seizure Susceptibility

\begin{tabular}{lccc}
\hline & & Mean Scores \\
\cline { 2 - 4 } Behavioral Measure & Unoperated & Frontal Cortex & Caudate Nucleus \\
\hline Latency to onset of myoclonus (sec) & 165.5 & 316.7 & 164.6 \\
Latency to onset of generalized seizures (sec) & 226.3 & 440.8 & 289.2 \\
Length of grand mal episodes (sec) & 99.9 & 169.9 & 255.3 \\
Incidence of myoclonic jerks & 15.3 & 22.2 & 3 \\
Incidence of status epilepticus & 2 & 1 & 5 \\
Incidence of postseizure deaths & 0 & 1 & 5 \\
\hline
\end{tabular}




\section{DISCUSSION}

Pentamethylentetrazol-induced seizures appeared more severe in rats with lesions of the caudate nucleus. In comparison with unoperated rats, the caudotomized rats showed heightened severity, as reflected in longer episodes of generalized seizures, increased incidence of myoclonic jerks, status epilepticus, and postconvulsive mortality. Compared with rats with lesions of the frontal cortex, the caudotomized subjects showed significantly greater incidence and more rapid onset of myoclonic jerks.

Compared with the unoperated rats, the subjects with lesions of the frontal cortex showed significantly higher incidence of myoclonic jerks, but less rapid onset of both myoclonus and generalized seizures. It was noteworthy that extent of lesion was significantly correlated with latency to onset of generalized seizures. The results of two earlier investigations appear relevant to these findings. Weiner and Morgan (1945) studied the interaction of cortical lesions and audiogenic seizures in the rat. Tests carried out 3 to 30 days postoperatively showed that, of the rats in the "prefrontal" and "motor" groups, only six evidenced seizures. Three of these, subjects 3,10 , and 17 , had lesions similar to those of the cortically lesioned group in the present study. Although 8 out of 10 of Weiner and Morgan's unoperated rats showed shorter seizure latencies when tested postoperatively, the latencies to seizure for all three frontal cortex subjects were longer after surgery than before. In another study, Adler (1966) observed the effects of hexaflurodiethylether seizures in cortically lesioned and sham-operated rats. In tests carried out 1 to 4 weeks after surgery, frontal lesion rats took significantly longer than control subjects to convulse. When tested 8 weeks after surgery, the position had reversed and the rats with lesions of the frontal cortex convulsed in significantly less time (Adler, 1966). In the present study, the rats with cortical lesions showed increased latencies when tested 10 weeks after operation. While it is possible that further tests carried out even later could have resulted in different findings, the results did suggest that, in terms of seizure onset, these subjects showed less susceptibility than the unoperated or caudotomized rats.

Various corticofugal and corticopetal fibers flow through the corpus striatum. This suggests the possibility that the changes in seizure behavior observed in caudotomized rats were due to disruption of these pathways rather than damage to the caudate nucleus itself. However, in the rat brain, the fibers "de passage" are spread diffusely throughout the striatum and do not form the compact tracts found in carnivores and primates (Zeman \& Innes, 1963). This indicates that, although lesions as restricted as those in the present study (see Figure 1) would be likely to transect some fibers, the majority of connections running through the caudate would remain intact.

The present investigations support the indications from electrophysiological (Gastaut et al., 1958; La Grutta, Amato, \& Zagami, 1971; Mutani, 1969; Walker, Andy, \& Poggio, 1955), pharmacological (Cools, Hendriks, \& Korten, 1975), and clinical studies (Spiegel et al., 1956) that the caudate nucleus is involved in the seizure phenomena of epilepsy. One possible explanation of this involvement concerns the caudate nucleus as a trigger mechanism responsible for the firing of the seizure. This concept is supported by the observations that the seizure threshold of the caudate nucleus is the highest of the convulsive-sensitive areas of the brain (Somogyi, Porszasz, \& Herpai, 1967; Umbach, 1959). In another study, Demetrescu, Demetrescu, and Iosif (1965) investigated seizure phenomena in cats before and after lesions of the caudate nucleus or the suprapontine reticular formation. Following lesions of either area, cortical seizures could be elicited at thresholds lower than those found necessary in the intact animal. These findings suggest that when seizure-eliciting stimuli are applied the central nervous system remains unreactive until stimulation levels exceed the caudate threshold. Once the threshold has been reached and seizure activity triggered off, the convulsions spread throughout the brain. In that there were no significant differences between the unoperated and caudotomized rats in latencies to the onset of myoclonus or generalized seizure, the present findings do not support the trigger hypothesis. It could be that latency is not necessarily a valid measure of seizure susceptibility and that an alternative technique, such as administration of graded amounts of convulsants, would reveal lowered thresholds to seizure onset in rats with lesions of the caudate nucleus.

However, a more feasible hypothesis concerns the caudate nucleus as part of an inhibitory system dampening ongoing seizure activity. Evidence for this view comes from the investigations of Mutani (1969), indicating that in convulsive states the caudate functions as part of a "braking emergency system" becoming activated only when seizure discharges rise above a critical level. This is supported by the observations that lesions of the caudate nucleus substantially prolonged seizure activity in the cat (Demetrescu, 1967). Conversely, it has been found that high-frequency stimulation of the caudate nucleus inhibited both behavioral and electrophysiological manifestations of epileptic seizure (La Grutta et al., 1971). In the present study, seizure responses were measured in terms of motor phenomena. It is noteworthy that the concept of the caudate nucleus as an inhibitor or modulator of seizure is consistent with the classical view of the role of the caudate nucleus in motor functioning (Kornhuber, 1974). 


\section{REFERENCES}

AdLer, M. W. Increased sensitivity to pentylenetetrazol and flurothyl following cortical ablations in rats. Journal of Pharmacology and Experimental Therapeutics, 1965, 148, 131-135.

ADLER, M. W. Time course of altered sensitivity to flurothyl following cortical ablations in rats. Journal of Pharmacology and Experimental Therapeutics, 1966, 153, 396-399.

ADLER, M. W. Laboratory evaluation of antiepileptic drugs-The use of chronic lesions. Epilepsia, 1969, 10, 263-280.

Cools, A. R., Hendriks, G., \& Korten, J. The acetylcholinedopamine balance in the basal ganglia of rhesus monkeys and its role in dynamic, dystonic, dyskinetic, and epileptoid motor activities. Journal of Neural Transmission, 1975, 36, 91-105.

DEMETRESCU, M. Ascending inhibitory and facilitatory influences controlling primary thalamo-cortical responsiveness. Brain $R \boldsymbol{R}$ search, 1967, 6, 36-47.

Demetrescu, M., Demetrescu, M., \& Iosif, G. The subcortical inhibitory structures and cortical seizure activity in cats. Proceedings of the Eighth International Congress of Neurology, Vienna, 1965, 265-268.

Gastaut, H., Naquet, R., \& Fischer-Williams, M. The pathophysiology of grand mal seizures generalized from the start. Journal of Nervous and Mental Disease, 1958, 127, 21-33.

HaYs, W. L. Statistics for psychologists. New York: Holt, Rinehart \& Winston, 1963.

KESNER, R. P. Subcortical mechanisms of audiogenic seizures. Experimental Neurology, 1966, 15, 192-205.

KIRKBY, R. J. The caudate nucleus and arousal in the rat. Journal of Comparative and Physiological Psychology, 1973, 85, 82-96.

Kornhuber, H. H. Cerebral cortex, cerebellum, and basal ganglia: An introduction to their motor functions. In F. O. Schmitt \& F. G. Worden (Eds.), The neurosciences third study program. Cambridge, Mass: MIT Press, 1974.

KRIEG, W. J. Connections of the cerebral cortex. I. The albino rat. A. Topography of the cortical areas. Journal of Comparative Neurology, 1946, 84, 221-259.
La Grutta, V., Amato, G., \& Zagami, M. T. The control of amygdaloid and temporal paroxysmal activity by the caudate nucleus. Experientia, 1971, 27, 278-279.

Mullan, S., Vailati, G., Karasick, J., \& Mailis, M. Thalamic lesions for the control of epilepsy. Archives of Neurology, 1967, 16, 277-285.

Mutani, R. Experimental evidence for the existence of an extrarhinencephalic control of the activity of the cobalt rhinencephalic epileptogenic focus. Epilepsia, 1969, 10, 337-350.

Somogyi, I., Porszasz, J., \& Herpai, S. Topography of the convulsion-sensitive area of the caudate nucleus. Acta Physiologica Academiae Scientiarum Hungaricae Tomus, 1967, 32, 253-262.

Spiegel, E. A., Wycis, H. T., Baird, H. W., \& Szekely, E. G. Functional state of basal ganglia in extrapyramidal and convulsive disorders. Archives of Neurology and Psychiatry, 1956, 75, 167.

Uмвасн, W. Electrophysiologie des Caudatum der Katze. Archiv für Psychiatrie und Nervenkrankheiten, 1959, 199, 553-575.

WAlker, A. E., ANDy, O. J., \& Poggio, G. F. The role of the basal ganglia in convulsions. Transactions of the American Neurological Society, 1955, 80, 158-161.

Wiener, H. M., \& Morgan, C. T. Effects of cortical lesions upon audiogenic seizures. The Journal of Comparative Psychology, 1945, 38, 199-208.

WINER, B. J. Statistical principles in experimental design. New York: McGraw-Hill, 1962.

Wycis, H. T., BAIRD, H. W., \& SPIEgel, E. A. Long range results following pallidotomy and pallidoamygdalotomy in certain types of convulsive disorders. Confinia Neurologia, 1966, 27, 114-120.

Zeman, W., \& InNES, J. R. Craigie's neuroanatomy of the rat. New York: Academic Press, 1963.

(Received for publication May 11, 1977; accepted June 9, 1977.) 